\title{
De la reactivación a la crisis: la industria argentina durante el ciclo de gobiernos kirchneristas
}

\section{From Reactivation to Crisis: Argentine Industry during the Cycle of Kirchnerist Governments}

\author{
Pablo Manzanelli ${ }^{1}$ \\ Facultad Latinoamericana de Ciencias Sociales, Buenos Aires, Argentina \\ Universidad Nacional de Quilmes, Buenos Aires, Argentina \\ pdmanzanelli@gmail.com \\ http://orcid.org/0000-0002-4683-9405

\section{Daniela Calvo} \\ Facultad Latinoamericana de Ciencias Sociales, Buenos Aires, Argentina \\ danielascalvo@gmail.com \\ http://orcid.org/0000-0002-1872-3122
}

Recibido: 28-06-19

Aprobado: 12-02-20

* Este trabajo se realizó bajo el patrocinio de la Agencia Nacional de Promoción Científica y Tecnológica, en el marco del Proyecto PICT-2016-3306, “Condicionamientos estructurales, macroeconómicos y sectoriales, y sus manifestaciones en el sector externo".

1 Doctor en Ciencias Sociales.

2 Licenciada en Economía. 


\section{Resumen}

El presente trabajo analiza las transformaciones registradas en el desempeño de la industria manufacturera argentina en el período 2003-2015, poniendo el énfasis en las causas de la fase de contracción sectorial que se advierte a partir de 2012. El supuesto es que la interrupción del crecimiento industrial, en el marco de la denominada "restricción externa", obedeció a un extenso período de subinversión en el ámbito manufacturero. En tal sentido, los hallazgos de esta investigación ponen en evidencia el reducido nivel de inversión de las grandes empresas industriales. Un aspecto novedoso, dada la ausencia de evidencias empíricas que permitan analizar la inversión sectorial en el sistema estadístico argentinosencia de evidencias empíricas que permitan analizar la inversión sectorial en el sistema estadístico argentino.

Palabras clave: crisis económica; industria argentina, gobierno kirchnerista.

\section{Abstract}

This paper analyzes the transformations recorded in the performance of the Argentine manufacturing industry in the period 2003-2015, emphasizing the causes of the contraction phase of the sector that is felt from 2012. The assumption is that the interruption of industrial growth, under the so-called "external constraint", was due to an extended period of sub-investment in manufacturing. In this sense, the findings of this research show the low level of investment of large industrial companies. A novel aspect, given the absence of empirical evidence to analyze the sector investment in the Argentine statistical system.

Keywords: economic crisis; argentina industry; Kirchner government.

¿Cómo citar este artículo? / How to quote this article?

Manzanelli, P. y Calvo, D. (2020). De la reactivación a la crisis: la industria argentina durante el ciclo de gobiernos kirchneristas. Sociedad y economía, (40), 119-142. https://doi.org/10.25100/sye.voi40.8140 


\section{Introducción}

La irrupción de la restricción externa (escasez de divisas), en la economía argentina, interrumpió la sostenida fase de reactivación fabril que se registró entre 2003 y 2011, cuando parecía haberse dejado atrás el largo proceso de desindustrialización y restructuración regresiva del entramado fabril que se había constatado durante el modelo de valorización financiera entre 1976 y 2001 (Basualdo, 2010).

Existe cierto consenso en la literatura respecto a la trayectoria industrial, sin embargo, las causas de la interrupción de la fase ascendente son materia de debate. A simple título ilustrativo, cabe señalar que algunos autores ponen el acento en la apreciación del tipo de cambio real y la emergencia de los desequilibrios macroeconómicos como los elementos que limitaron el crecimiento de la economía en general y de la industria en particular (véase, por ejemplo, Gerchunoff y Llach, 2018; Broda y Asociados, 2015; Levy-Yeyati y Castro, 2012). Otros se apoyan en los límites típicos de la restricción externa en el marco de la ausencia de políticas industriales (Abeles y Amar, 2017; Kulfas, 2016; Castells y Schorr, 2015; Manzanelli y Basualdo, 2017; Lavarello y Sarabia, 2015; Porta, Santarcángelo y Schteingart, 2014; Schorr y Wainer, 2017; entre otros).

En ese marco, el presente trabajo procura analizar las transformaciones registradas en el desempeño de la industria manufacturera argentina, en el período 2003-2015, poniendo el énfasis en las interrelaciones entre la trayectoria sectorial y los límites que se expresaron en el sector externo. Ello, bajo el supuesto de que la interrupción del crecimiento industrial en el marco de la irrupción de la restricción externa, en realidad obedeció a un extenso período de subinversión en el ámbito manufacturero, que tuvo su epicentro en las grandes compañías industriales.

Se trata de un elemento que permite precisar el análisis de los factores que incidieron en la irrupción de la restricción externa actual y en cuyo derrotero subyace, como lo plantean diversas investigaciones previas, la insuficiente política industrial para impulsar la inversión sectorial durante el ciclo kirchnerista. Es a partir de estas premisas que se procurará aportar al análisis del desempeño industrial en este período, incorporando el examen de la incidencia del proceso inversor. Cabe señalar que esta cuestión ha sido escasamente tratada por la literatura, debido a la escasez de evidencias empíricas en lo que concierne a la inversión industrial ${ }^{3}$.

Con tal finalidad, el trabajo se estructura de la siguiente manera. En la próxima sección, se pasa revista al desempeño industrial agregado durante el período 2003-2015 y su relación con la evolución de las importaciones. En el tercer apartado, se examina el vínculo entre la estructura fabril y la dependencia de las importaciones, así como el análisis de las causas que explican la interrupción del crecimiento durante el final del ciclo kirchnerista, a partir del comportamiento de las inversiones industriales. A pesar de las limitaciones que tuvo la política industrial en esta etapa -aspecto del que se han ocupado otras investigaciones (Lavarello y Sarabia, 2015; Lavarello, 2017)-, en el cuarto apartado se pasa revista a algunas experiencias incipientes que, de haber alcanzado una magnitud y maduración superior, podrían haber actuado como vía inductora de una mayor inversión sectorial. Finalmente, cierran este trabajo unas breves conclusiones finales.

\section{La trayectoria industrial y la elevada elasticidad de las importaciones}

Durante el modelo de valorización financiera, iniciado a partir de la instauración de la última dictadura cívico-militar, se puso en

3 Una excepción en este sentido, a pesar de que su abordaje haya sido secundario en los objetivos del trabajo y, por ende, de un alto grado de generalidad, es el de Goldstein, Kulfas y Zack (2017), en el que se realiza una estimación a partir de la producción y el grado de utilización de la capacidad instalada. Allí se concluye que la capacidad instalada industrial crece por debajo de la producción, entre 2003 y 2013. 
marcha un largo proceso de desindustrialización de la economía argentina que perduró hasta su crisis terminal en $2002^{4}$. Al respecto, cabe señalar que mientras el valor agregado industrial fue en 2002 un 15,3\% inferior al vigente en 1976, el PIB fue 30,9\% superior (Figura 1).

Figura 1. Evolución del valor agregado bruto industrial y del PIB en precios constantes*, 1976-2015 (número índice base 1976=100)

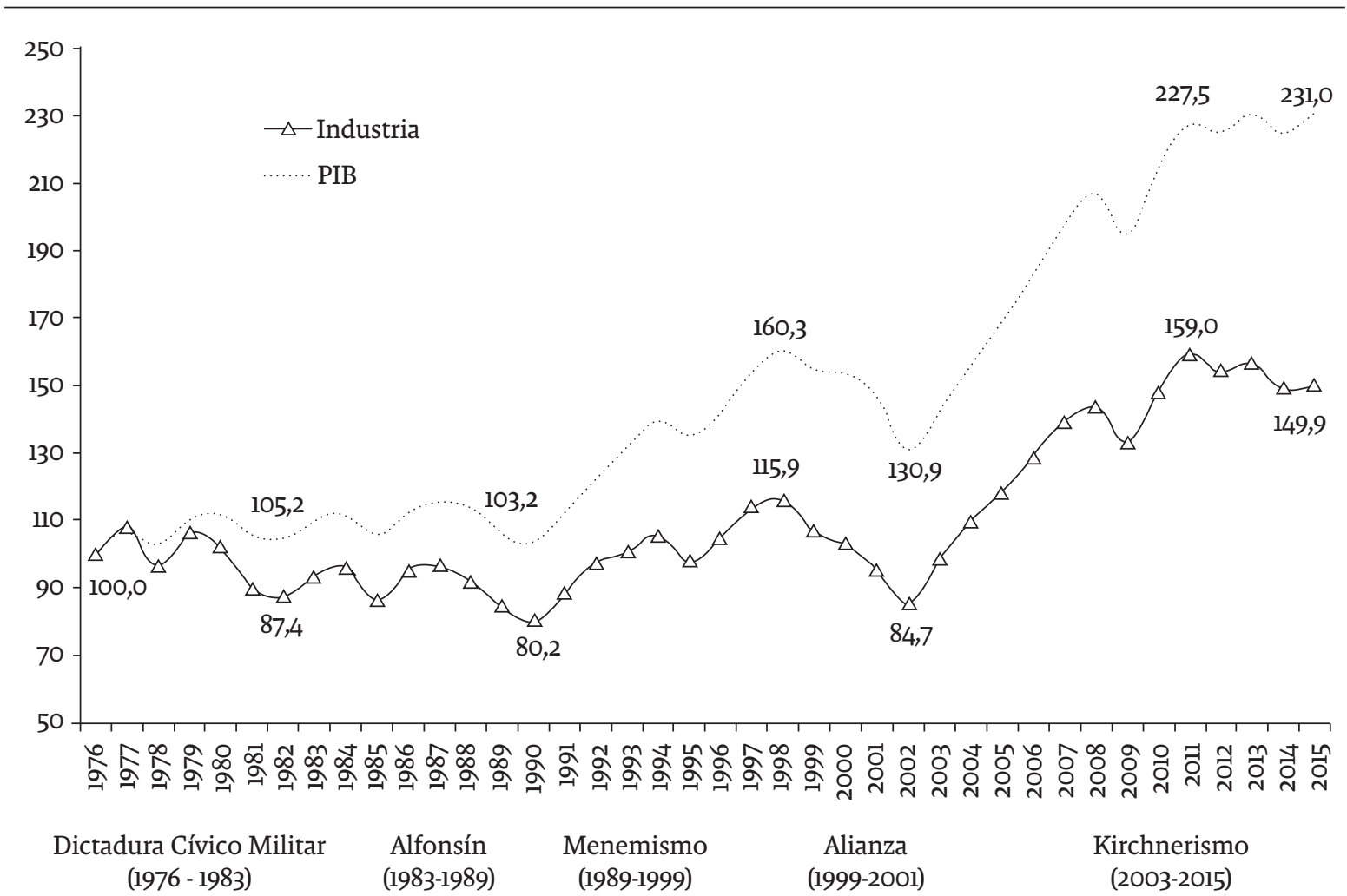

Nota: *Se empalmó la serie del año base 2004 (revisada en 2016) con la serie histórica empalmada por INDEC, con año base 1993 (1980-2003) y Ferreres (2004) para el período 1976-1979.

Fuente: elaboración propia basada en INDEC (2018) y Ferreres (2004).

Se trató, de todos modos, de un fenómeno que reconoció distintas etapas. Desde el golpe de Estado de 1976 y hasta el fin de la administración de Alfonsín, en 1989, tuvo lugar una profunda contracción del valor agregado industrial en un contexto de estancamiento económico. Esta fase no solo incluyó la destrucción neta del stock manufacturero, sino también la disolución de una parte importante del entramado de eslabonamientos y articulaciones intra e interindustriales. Dicho proceso implicó la pérdida tanto de las capacidades como de la densidad tecnológica que se había

4 En línea con el neoliberalismo que se imponía, a nivel internacional, este patrón de acumulación se sustentó en la valorización financiera a través del endeudamiento externo y la fuga de capitales al exterior. En términos más específicos, el diferencial positivo entre la tasa de interés local y la internacional garantizó altas tasas de retorno en la esfera de las finanzas. Así, la deuda externa privada (con bajas tasas de interés en buena parte del período 1976-2001), a la que accedió la cúpula empresarial, jugó un rol central en este patrón de acumulación. También fue decisivo, sin duda, el papel del Estado a través del endeudamiento público: de esta manera se garantizaron tanto los recursos para sostener las altas tasas locales (y, por ende, las ganancias financieras) como las divisas que se requerían para la fuga de capitales (Basualdo, 2010). 
alcanzado durante la etapa de industrialización sustitutiva.

Por su parte, a pesar de la expansión industrial que se verificó entre 1991 y 19985, no solo perduró la desindustrialización relativa durante todo el decenio, sino que también se profundizaron las heterogeneidades sectoriales, generando cambios sustantivos en el perfil de especialización (en beneficio de las ramas vinculadas a la explotación de recursos naturales, la producción de bienes de uso difundido y aquellas amparadas en regímenes especiales como es el caso de la industria automotriz). Asimismo, se agudizó el proceso de concentración y centralización del capital, en el marco de un desempeño agregado en el que persistió de manera incesante la destrucción de la masa crítica con que contaba el aparato manufacturero doméstico (Azpiazu y Schorr, 2010). La escasa sostenibilidad de la fase expansiva inicial se puso de manifiesto con la profunda contracción fabril, entre 1998 y 2002, que alcanzó una caída del $26,9 \%$, ubicando a la producción industrial en el mismo nivel que al inicio de la década de 1990.

Aunque algunas visiones sostienen que el proceso de desindustrialización que tuvo lugar en Argentina, y en el resto de los países latinoamericanos, se asemejó a lo que ocurrió en los países centrales -donde la maduración de los sectores fabriles determinó una disminución de sus precios relativos, debido al incremento de la productividad, la expansión de sectores de servicios asociados a su expansión y la estrategia de internacionalización productiva (De la Torre, Levy-Yeyati y Pianknaguru, 2013)-, la evidencia empírica demuestra lo contrario para el caso argentino. Es decir, se trató de un proceso de

5 Según Basualdo (2003), "La acentuada expansión de la producción industrial durante la "etapa de oro" de la Convertibilidad parece ser el resultado de una rápida recuperación de la profunda retracción que registra durante el momento más serio de la crisis, impulsada por el incremento del consumo y porque la competencia importada derivada de la apertura económica es relativamente incipiente. Durante esta etapa, el propio sector industrial contribuye a la expansión del consumo popular ya que se incrementa el salario real aunque evoluciona por debajo de la productividad y se incrementa la expulsión de mano de obra" (p. 45). desindustrialización basado en la destrucción del aparato fabril y la restructuración regresiva de su fisonomía (Azpiazu y Schorr, 2010).

Con el agotamiento de la valorización financiera y el estallido de la crisis, en 2001 , el proceso de desindustrialización fue interrumpido. A partir de 2003, se inició una notable recuperación del sector manufacturero cuya expansión fue sumamente acentuada hasta 2007, para luego ingresar en una fase de marcada desaceleración de la actividad (con las fenomenales excepciones del bienio 2010-2011) y con, incluso, una tendencia decreciente de la producción industrial a partir de 2012.

Durante la primera etapa del ciclo de gobiernos kirchneristas (2003-2007), la industria experimentó un acelerado ritmo de expansión, tanto en términos de los registros históricos como respecto a los estándares de los principales países latinoamericanos en ese período ${ }^{6}$. Con sus matices y especificidades, las industrias latinoamericanas (y sus respectivas economías) revelaron ciertos sesgos que, a la vez, no estuvieron desvinculados del propio escenario internacional en el que se insertaron. Sin embargo, en el atípico ejemplo argentino -por la larga recesión previa y las altas tasas de crecimiento posteriores- tales factores generales parecieron subordinarse a los componentes endógenos, que asumieron una intensidad superior a la que adoptaron en las restantes industrias (y economías) de la región.

La devaluación implementada, a principios de 2002, trajo aparejado un profundo reordenamiento de los precios relativos de la economía (incluyendo, en especial, al tipo de cambio real y los salarios) que devinieron tanto en un encarecimiento de los productos importados como en un aumento de la rentabilidad. Ciertamente, no existe una asociación automática entre el tipo de cambio y las ventas al exterior que permita establecer conclusiones a priori. Sin embargo,

6 Mientras que la industria argentina creció al 10,4\% anual acumulativo, las industrias de Brasil y México crecieron en torno al 3,5\% anual entre 2002 y 2007 (datos correspondientes a la CEPAL). 
no caben dudas de que en un escenario internacional en expansión, con incremento de los precios de algunos commodities industriales, la elevación del tipo de cambio real permitió a varios oligopolios fabriles (en virtud de los beneficios emanados de la reducción de los costos laborales) incrementar su capacidad de exportación y aprovechar tales condiciones internacionales. Los sectores cuyos comportamientos obedecieron a esta dinámica fueron alimentos y bebidas, refinación de petróleo y el sector automotriz (Bekerman, Dulcich y Gaite, 2018).

Por su parte, la paulatina pero sistemática recuperación del consumo interno, a partir de 2003, basada en una significativa generación de puestos de trabajo y la recomposición de los salarios reales, tras su reducción en 2002, fortalecieron al consumo interno, en un contexto en el cual el tipo de cambio real mantuvo cierta protección interna frente a los bienes foráneos. Ello incidió en la acelerada reactivación fabril, primero, a partir de un mayor aprovechamiento de las capacidades instaladas ociosas del largo período recesivo anterior $\mathrm{y}$, posteriormente, con base en una ampliación -que devino acotada y temporaria- de las capacidades productivas instaladas en un escenario de rentabilidades extraordinarias.

Cabe señalar, sin embargo, que no existe una visión unánime respecto de los factores que incidieron en la rápida recuperación industrial y de la economía, en general, en la primera etapa kirchnerista. Por ejemplo, Frenkel, Damill y Rapetti (2015) sostienen como elemento preponderante al tipo de cambio competitivo y estable vigente, en la primera parte del período kirchnerista. La tesis del "viento de cola", que está más afincada en el "sentido común" que en la bibliografía especializada, atribuye un papel más importante al favorable nivel de precios internacionales (Levy-Yeyati y Cohan, 2012). Diversos estudios de corte heterodoxo plantean la convergencia de diferenteselementos internos como el tipo de cambio estable, el papel de la demanda agregada basada en la expansión del empleo, y los salarios y las políticas expansivas de ingreso (Manzanelli y Basualdo, 2017; Abeles y Amar, 2017; Coatz y Schteingart, 2016; Castells y Schorr, 2015; Fernández-Bugna y Porta, 2007). Por su parte, Amico (2013) enfatiza la importancia que tuvo el incremento de la demanda doméstica estimulada por una política fiscal activa.

Como se mencionó, a partir de 2008 se interrumpió este proceso de acelerada expansión. Tras una considerable contracción en el marco de la irrupción de la crisis mundial (caída del $7,3 \%$ en 2009), se reimpulsó el ciclo de crecimiento industrial en 2010 y 2011 (con alzas del $10,9 \%$ y $7,7 \%$ anual, respectivamente). Sin embargo, ese impulso no logró mantenerse y la industria entró en una fase recesiva, registrándose así una caída del 1,5\% anual acumulativo entre 2011 y 2015.

Entre los factores explicativos, resulta indudable el impacto de la crisis mundial y su correlato posterior en las economías de Brasil y China, y en la reducción de ciertos precios internacionales. La conjunción de estos factores trajo aparejada una importante caída de las exportaciones industriales entre 2011 y 2015. Sin embargo, también incidieron en el retroceso fabril los límites típicos que la restricción externa le impone al crecimiento industrial y de la economía, en general, en estructuras subdesarrolladas como la de Argentina. Es decir, la incapacidad para contar con las divisas necesarias para las importaciones y la recurrencia a las devaluaciones que acarrean procesos inflacionarios, caídas del salario real y, por ende, del consumo interno (Braun y Joy, 1968; Diamand, 1973).

Sin embargo, a diferencia de lo que ocurrió en el modelo de industrialización por sustitución de importaciones vigente en la economía argentina, entre 1930 y 1976, la restricción externa en esta etapa no se produjo en circunstancias de una mayor integración del espectro fabril y ciertos avances tecnológicos. A modo de hipótesis, lo que se puso de manifiesto fue un largo período de subinversión en el ámbito manufacturero, que tuvo su epicentro en las grandes compañías industriales (Manzanelli, 2019). Este hecho terminó actuando como un verdadero "talón de Aquiles" para el sostenimiento de la fase expansiva. 
La baja propensión inversora en el ámbito fabril será retomada en el próximo apartado, pero lo que interesa señalar aquí es que se constituyó como una variable de relevancia, no solo como limitante del proceso de crecimiento sectorial, sino como uno de los elementos que potenciaron la restricción externa de la economía en su conjunto. Esto es así porque las ganancias no reinvertidas se tendieron a canalizar por la vía de la fuga de capitales y también porque la reducida inversión, del gran empresariado industrial, aumentó la dependencia de las importaciones para el crecimiento económico. Es decir, la industria se expandió basada en una matriz insumo-producto desarticulada y escasamente integrada, sin que se generaran los cambios significativos necesarios para hacerla compatible con el sendero de crecimiento. Uno de los efectos, agregados a esta cuestión, puede observarse en la elevada elasticidad de las importaciones respecto al crecimiento industrial (Figura 2). Mientras que el valor agregado industrial se expandió el 61,9\%, entre 2003 y 2011, las importaciones industriales en precios constantes lo hicieron al 266,1\%, es decir, tuvieron más de cuatro veces el nivel de actividad. Esto denota el carácter "divisa-dependiente" de la estructura industrial7.

Posteriormente, cuando la industria inició la etapa de retroceso sectorial a partir de 2012 y se aplicaron diversas políticas de regulación de las importaciones -como fue el caso de la ampliación de las licencias no automáticas de importación (Resolución del Ministerio de Industria $\mathrm{N}^{\circ}$ 45/2011) y posteriormente las declaraciones juradas anticipadas DJAI (Resolución General AFIP $\mathrm{N}^{\circ} 3252 / 12$ y 3255/12)-, las compras industriales al exterior se contrajeron considerablemente.

$\mathrm{Al}$ respecto, cabe señalar que el ritmo de crecimiento de las importaciones de productos industriales fue mucho más acelerado que el de las exportaciones de este mismo rubro. Así se generó un elevado deterioro de la balanza comercial industrial, que pasó de un superávit de 9.759 millones de dólares, en 2002, a un déficit de 6.881 millones, en 2011, para luego acrecentarse a

Figura 2. Evolución del PIB industrial y de las importaciones industriales en precios constantes, 1993-2015 (número índice base 2003=100)

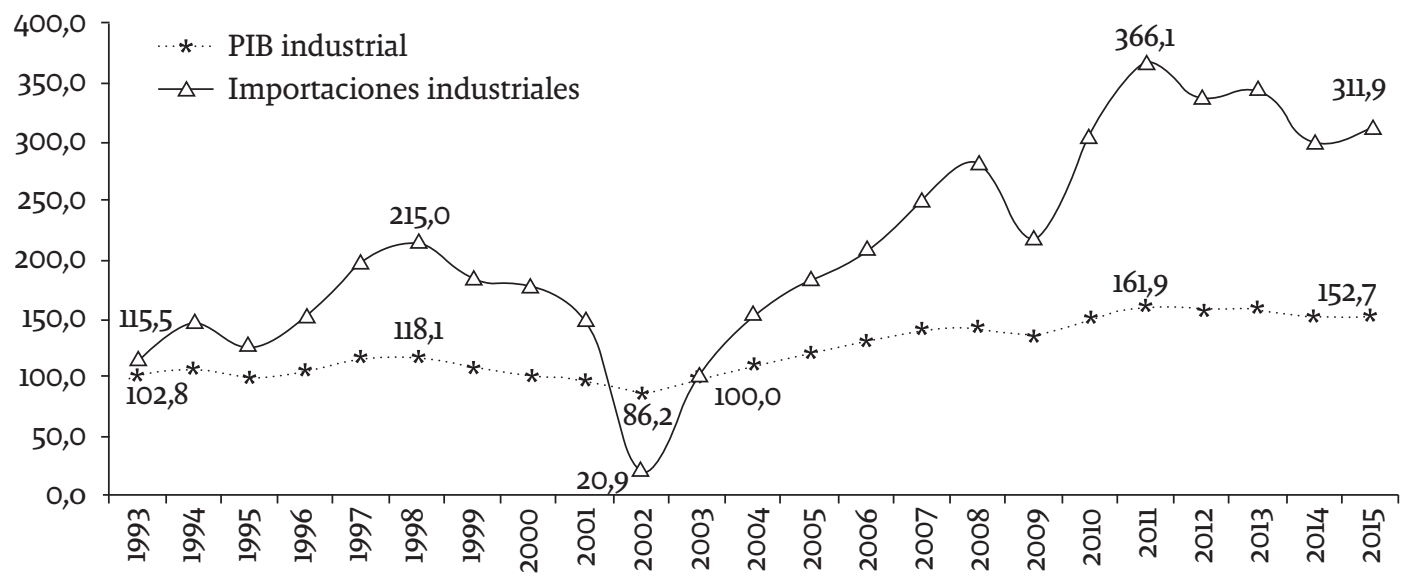

Nota: * Se deflactaron las importaciones con el IPI de las importaciones.

Fuente: elaboración propia basada en INDEC (2018), el CEP (2016) y el Ministerio de Producción y Trabajo (2018).

7 Abeles y Amar (2017) constataron la desarticulación del entramado intersectorial entre 1976 y 2003, causado principalmente por el incremento de las importaciones en todos los procesos productivos, especialmente en las actividades con mayor contenido tecnológico. Este proceso generó un incremento del perfil importador de la estructura productiva. 
10.829 millones, en 2015 , a pesar de los controles a las compras del exterior (Figura 3).

En suma, las evidencias aportadas hasta aquí permiten corroborar tanto la trayectoria industrial que registró la economía argentina durante el ciclo kirchnerista, como la importancia que tuvo el desempeño industrial en la conformación del cuello de botella, en el sector externo, en la última etapa. No ocurre lo mismo respecto a las hipótesis que se vertieron sobre las causas principales de ambos fenómenos. Es decir, que si bien se propusieron explicaciones sobre tal desempeño, resulta insuficiente el sustento empírico en el que se apoyan las mismas. Es por eso que el propósito de los próximos apartados es el de avanzar en una aproximación a los fundamentos de la hipótesis que guía este trabajo: el impacto que tuvo el proceso de subinversión en la recesión fabril y la emergencia de la restricción externa durante la fase final del ciclo de gobiernos kirchneristas.

\section{La escasa diversificación sectorial, la dependencia de las importaciones y el reducido nivel de inversión}

La elevada elasticidad de las importaciones, que fue expuesta precedentemente, no está para nada disociada de la escasa diversificación sectorial que se puso de relieve durante el ciclo de gobiernos kirchneristas. Una primera aproximación a la misma, consiste en examinar la evolución de la estructura industrial a partir del peso relativo de las principales ramas de actividad en el valor agregado industrial. Se trata de examinar, en última instancia, las dificultades que experimentó el proceso de crecimiento

Figura 3. Exportaciones, importaciones y saldo comercial de productos industriales en dólares corrientes, 1993-2015 (millones de dólares)

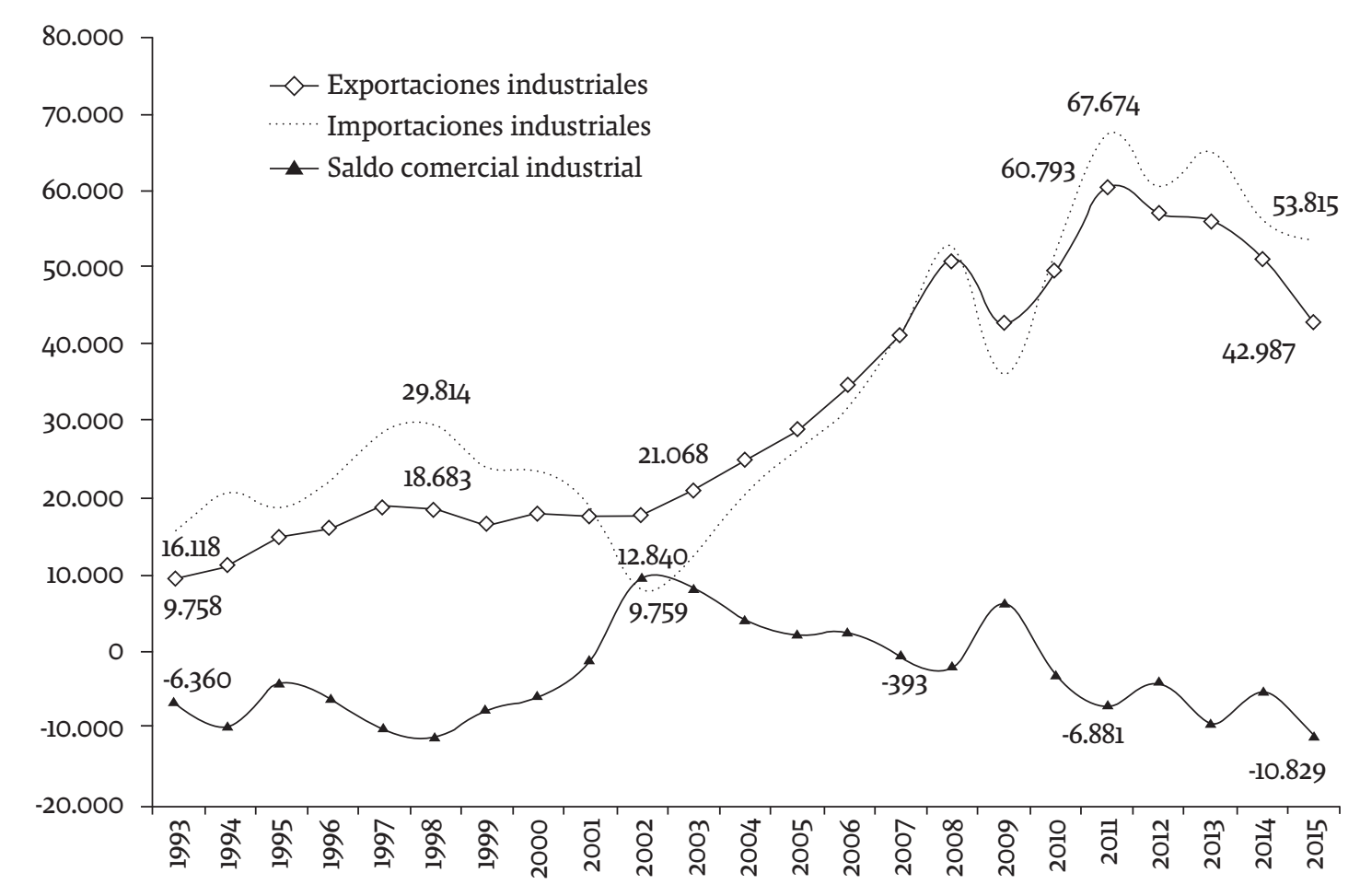

Fuente: elaboración propia basada en el INDEC (2018), el CEP (2016) y el Ministerio de Producción y Trabajo (2018). 
industrial para alterar su perfil de especialización tecno-productivo, después de las consecuencias que tuvo la valorización financiera en materia de la pérdida de eslabonamientos y articulaciones intra e interindustriales.

Debido a que la ausencia de cambio estructural ya fue tratada en trabajos previos (Porta y Fernández-Bugna, 2011; Schorr, 2013), en esta investigación solo se hará una referencia general a la misma para avanzar en el análisis de los límites que tuvo la diversificación sectorial en este período.

Las evidencias que constan en la Tabla 1 muestran que, en 2003 , el $68,8 \%$ de la estructura fabril, medida a través del peso en el valor agregado industrial, estaba compuesta por ocho sectores: alimentos y bebidas, sustancias $\mathrm{y}$ productos químicos, metales comunes, maquinaria y equipo, caucho y plástico, minerales no metálicos, prendas de vestir y vehículos automotores. Tras el acelerado crecimiento y la contracción industrial, a partir de 2011 no se advierten modificaciones significativas en la importancia relativa de estos sectores: más bien, su peso relativo se incrementó al 71,1\%, en 2015.

Más allá de su predominio productivo, las tasas de crecimiento fueron heterogéneas en los ocho rubros mencionados. Entre los de más acelerada expansión, se encuentra la industria de maquinaria y equipo (en especial maquinaria agrícola, tractores, línea blanca, aire acondicionado), la de minerales no metálicos, la automotriz y la química. En la generalidad de los casos, se trata de actividades que acentuaron significativamente sus desbalances de comercio exterior, al final de los gobiernos kirchneristas. $\mathrm{Al}$ respecto, se destaca el caso de maquinaria y equipo (cuyo déficit comercial trepó a 6.364

Tabla 1. Participación de las ramas fabriles en el PBI industrial, tasa anual acumulativa del valor agregado y saldo comercial por sectores de actividad, 2003-2015 (porcentajes y millones de dólares)

\begin{tabular}{|c|c|c|c|c|c|}
\hline & \multicolumn{2}{|c|}{$\begin{array}{c}\text { Participación en el PIB } \\
\text { industrial (\%) }\end{array}$} & \multirow{2}{*}{$\begin{array}{c}\begin{array}{c}\text { Tasa anual } \\
\text { acumulativa (\%) }\end{array} \\
2003-2015\end{array}$} & \multicolumn{2}{|c|}{ Saldo comercial (Mill. USD) } \\
\hline & 2003 & 2015 & & 2003 & 2015 \\
\hline Alimentos y bebidas & 25,6 & 25,8 & 3,6 & 9.020 & 21.715 \\
\hline Química & 13,2 & 14,3 & 4,3 & -1.556 & -6.015 \\
\hline Metales comunes & 9,6 & 6,9 & 0,8 & 939 & 1.165 \\
\hline Maquinaria y equipo & 4,0 & 5,9 & 7,1 & -1.246 & -6.364 \\
\hline Caucho y plástico & 5,0 & 5,0 & 3,4 & -293 & -1.272 \\
\hline Minerales no metálicos & 3,5 & 4,6 & 6,1 & -41 & -538 \\
\hline Prendas de vestir & 4,6 & 4,3 & 3,0 & 29 & -179 \\
\hline Vehículos & 3,4 & 4,2 & 5,5 & -41 & -2.608 \\
\hline Productos de metal & 5,1 & 4,2 & 1,9 & -193 & -1.145 \\
\hline Refinación de petróleo & 4,5 & 3,4 & 1,2 & 2.235 & -1.521 \\
\hline Muebles y colchones & 3,2 & 3,3 & 3,8 & 43 & -790 \\
\hline Edición e impresión & 3,4 & 3,2 & 3,0 & 5 & -30 \\
\hline Papel & 3,5 & 3,2 & 2,8 & -101 & -734 \\
\hline Textiles & 2,9 & 2,7 & 3,0 & -144 & -765 \\
\hline Curtido y cuero & 2,0 & 1,9 & 3,2 & 636 & 263 \\
\hline Equipos de radio, tv y comunic. & 0,2 & 1,7 & 23,4 & -436 & -4.496 \\
\hline Maq. y aparatos eléctricos & 1,7 & 1,7 & 3,2 & -355 & -2.725 \\
\hline Madera & 2,3 & 1,5 & $-0,3$ & 106 & -50 \\
\hline Instrumentos médicos y ópticos & 0,7 & 0,9 & 5,1 & -260 & -1.782 \\
\hline Tabaco & 0,8 & 0,5 & $-0,6$ & 4 & -2 \\
\hline Maq. de oficina, contabilidad e inform. & 0,4 & 0,5 & 6,3 & -475 & -1.290 \\
\hline Equipos de transporte & 0,5 & 0,4 & 1,0 & 354 & -1.665 \\
\hline Total Industria & 100,0 & 100,0 & 3,6 & 8.228 & -10.829 \\
\hline
\end{tabular}


millones de dólares en 2015), la industria química (-6.015 millones de dólares), y la producción automotriz (-2.608 millones).

Resulta especialmente interesante destacar que en este grupo de actividades dinámicas y con importantes déficits de comercio exterior, se ubica un rubro de escasa envergadura en la matriz fabril, pero de suma importancia en materia de la demanda de divisas. Tal es el caso de la industria de equipos de radio, televisión y comunicaciones, uno de los pilares centrales de la industria electrónica de consumo de Tierra del Fuego ${ }^{8}$, a través de la producción de celulares, televisores, reproductores de DVD, equipos de audio, etc. Como se puede observar en la Tabla 1, el crecimiento del sector fue del 23,4\% anual acumulativo, durante el período 2003-2015, en tanto que el déficit comercial trepó a 4.496 millones de dólares, en $\mathbf{2 0 1 5}$, cuando era de 436 millones, en 2003.

Las otras actividades donde figura la industria de Tierra del Fuego, como es el caso de maquinaria y equipo (allí se registran los aires acondicionados, por ejemplo) y maquinaria de oficina, contabilidad e informática (donde se contabilizan las computadoras) también experimentaron altas tasas de crecimiento ( $7,1 \%$ y $6,3 \%$ anual, respectivamente) y acentuados déficits en su respectivo saldo comercial (-6.364 y -1.290 millones de dólares en 2015).

En suma, en este plano agregado se evidencia la ausencia de modificación de la estructura fabril con, incluso, un leve aumento en la significación estructural de un número acotado de ramas industriales que no avanzaron, sino más bien lo contrario, en un proceso de sustitución de importaciones de esos bienes. De allí la profundización del deterioro del saldo comercial en tales sectores

8 En 1972, se creó, en la provincia de Tierra del Fuego, un Régimen de Promoción que otorga beneficios fiscales y aduaneros con el objetivo de fomentar la proliferación de actividades económicas (Ley $\mathrm{N}^{\circ}$ 19.640/72, -Poder Ejecutivo Nacional Argentino, 1972-). Debido a la apertura comercial y a las modificaciones operadas en las formas de producción de la electrónica a nivel mundial, muchas empresas dedicadas a la producción de este tipo de bienes se radicaron bajo el amparo del Régimen de Promoción durante los últimos años de la década del setenta (Nochteff, 1984). Este sector tuvo especial impulso a partir del año 2008 (ver apartado 4). y el aumento de la "divisa-dependencia" de los productos industriales para la expansión general de la economía. Esta constatación no alcanza, de todos modos, para evaluar si la expansión económica fue realizada con base en una matriz insumo-producto desarticulada y escasamente integrada, que potencie los requerimientos de importaciones. Con tal finalidad, en la Figura 4 se contrastan las tasas de crecimiento de las ramas industriales con el peso que tienen las importaciones en el consumo aparente de las mismas. Cabe señalar que tales importaciones son fundamentalmente bienes intermedios, insumos y bienes de capital, ya que los bienes de consumo final explicaron apenas el $11 \%$ de las importaciones totales del país, en el promedio del período 2003-2015, según datos de INDEC.

La comparación de las tasas de crecimiento con las importaciones sobre el consumo configura cuadrantes diferenciados por el promedio industrial de ambos indicadores. De allí que, por ejemplo, en el cuadrante superior derecho se ubiquen las ramas que más crecieron en el período 2003-2015 y que tienen un mayor ratio de importaciones sobre el consumo aparente. En tanto que en el cuadrante inferior izquierdo están las ramas de menor crecimiento y de menor incidencia de importaciones en el consumo. Asimismo, consta en la misma Figura 4 una estratificación del coeficiente de integración vertical de la rama de actividad, medida como la relación entre el valor agregado y el valor de producción sectorial.

En efecto, las evidencias aportadas por la Figura 4 confirman algunas de las afirmaciones precedentes. Es decir, que varias de las ramas industriales más dinámicas durante el ciclo kirchnerista fueron justamente las que detentan una superior demanda de importaciones y una baja o media integración vertical en sus actividades. Esto tendió a aumentar la "divisa-dependencia" de la industria local, tanto por la escasa sustitución de importaciones que alcanzaron como por las altas necesidades de importaciones que se requieren para su expansión.

Dos ramas son emblemáticas de este tipo de crecimiento industrial: la industria automotriz y la del complejo electrónico de consumo de Tierra del Fuego. En ambos casos, las ramas que integran esos sectores se ubicaron claramente en el cuadrante de los 
Figura 4. Tasa anual acumulativa del valor agregado, coeficiente de integración e importaciones sobre consumo aparente* de la industria manufacturera. Promedio 2003-2015 (porcentajes)

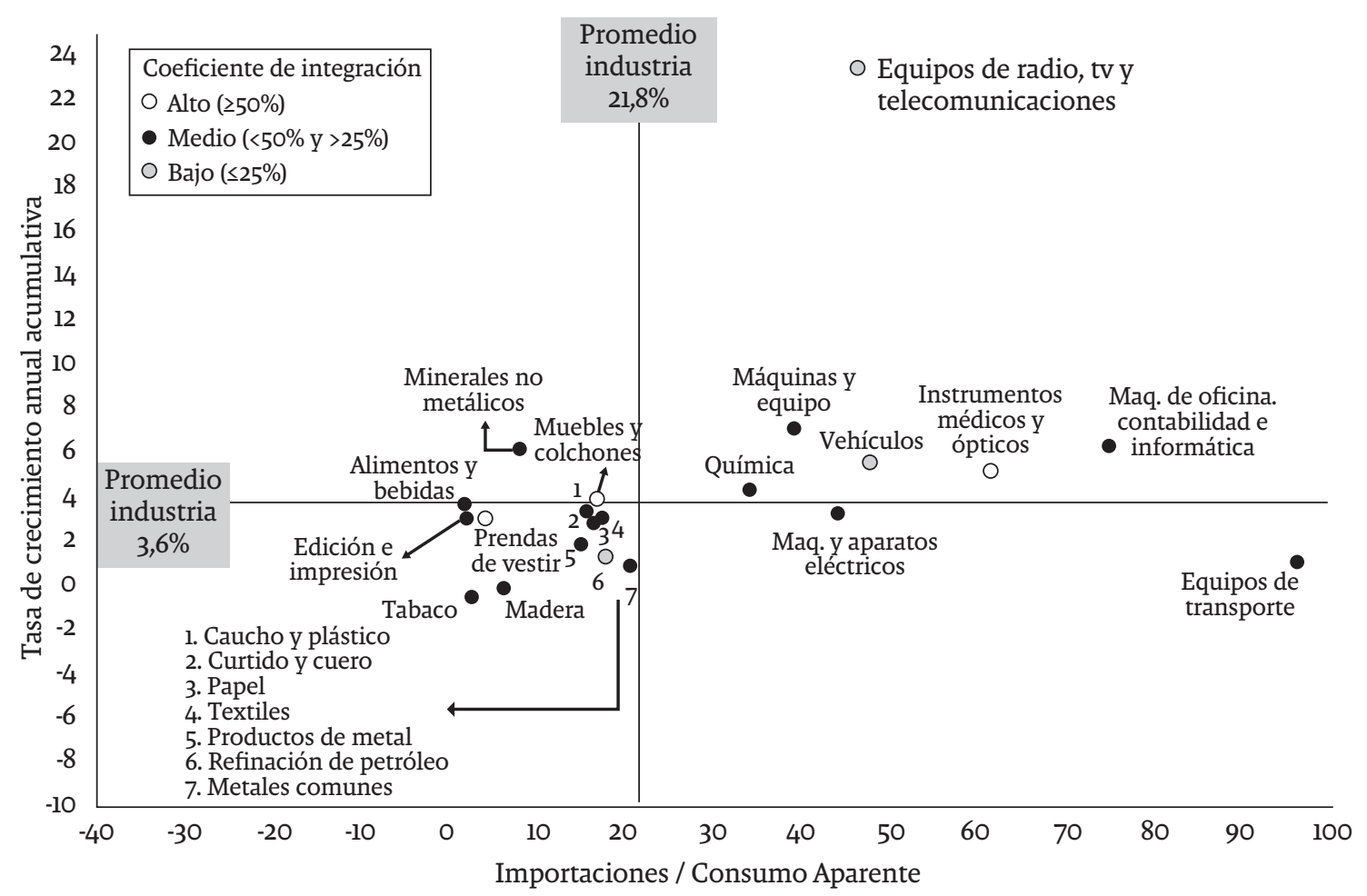

Nota: *El consumo aparente fue calculado a partir de la adición del valor bruto de producción (VBP), y las importaciones y la sustracción de las exportaciones. Por su parte, el coeficiente de integración surge del cociente entre el valor agregado bruto (VAB) y el VBP.

Fuente: elaboración propia basada en el INDEC (2018) y el Ministerio de Producción y Trabajo (2018).

"ganadores" -desde el punto de vista del crecimiento durante 2003-2015-, pero que combinan uno de los niveles más altos de importaciones respecto al consumo y reducidos coeficientes de integración vertical. Se trata del caso de vehículos automotores, equipos de radio, televisión y comunicaciones, algunos rubros que las cuentas nacionales registran en la industria de maquinaria y equipo (equipos de aire acondicionado, compresores de aire), y en la de maquinaria de oficina, contabilidad e informática (computadoras portátiles -notebooks, netbooks y tablets-, monitores).

En todos ellos, se advierte una abultada demanda de importaciones a raíz de la marcada desintegración vertical de sus actividades. Por ejemplo, en equipos de radio, televisión y comunicaciones el coeficiente de integración fue de apenas el 15,7\%, en tanto que en la industria automotriz fue de $18,3 \%$ (datos correspondientes al promedio del período 2003-2015). En efecto, se trata de cuasi enclaves importadores, cuyos coeficientes de integración vertical son marcadamente inferiores al magro nivel de la industria en su conjunto (31,5\%).

En cuanto a la producción automotriz, vale decir que su desempeño, en el período 2003-2015, evidenció una fuerte expansión de la armaduría automotriz -es decir, de las terminales automotrices- que no fue contemporánea a un crecimiento proporcional, ni mucho menos, de la producción interna de autopartes y neumáticos. Esto ocurrió en el marco del escaso interés de las transnacionales automotrices por impulsar 
el desarrollo de proveedores locales en la nueva división internacional y/o regional del trabajo sectorial -especialmente en el marco del Mercosur-, y las escasas iniciativas de la política industrial para mitigar esa tendencia (González y Manzanelli, 2012).

Por su parte, la industria electrónica de consumo en Tierra del Fuego, que desde sus inicios se caracterizó como la "tecnología del destornillador" debido a su prácticamente nulo grado de integración local- no modificó su matriz de especialización de carácter "ensamblador y mercado-internista" durante el ciclo kirchnerista (Nochteff, 1984; Azpiazu, Basualdo y Nochteff, 1988; Schorr y Porcelli, 2014). Esta característica está asociada a las formas de producción de la industria electrónica a nivel internacional: dentro de la cadena de valor mundial, países periféricos -como Argentina o Brasil- se insertan en la producción de bienes electrónicos destinados a sus mercados internos y producidos; en general, a partir del ensamble de componentes importados (Santarcángelo y Perrone, 2015; Bekerman y Dulcich, 2018).

Bajo estas circunstancias, el aliento al consumo de estos bienes -mediante políticas dirigidas específicamente, como fue el Plan Conectar Igualdad, Ahora 12, el propio régimen fueguino, el Procreauto, etc.- trajo aparejada una presión relevante de las importaciones tanto de bienes finales como, fundamentalmente, de bienes intermedios y de capital.

De este modo, tanto el sector automotriz como el de la industria electrónica de Tierra del Fuego se constituyeron como una fiel expresión del tipo de crecimiento industrial y sus limitaciones estructurales. Es decir, las propias características morfológicas, de este tipo de crecimiento industrial, terminaron actuando como vía inductora de un acelerado crecimiento de las importaciones fabriles para hacer compatibles el nivel de oferta (tanto de bienes finales como principalmente intermedios, de insumos y de capital) y el nivel de demanda, en un escenario con significativos impulsos al consumo. De este modo, se fue profundizando la "divisa-dependencia" de la industria local y, con ella, se fue deteriorando el déficit sectorial del saldo comercial. Esto presionó, junto a otros factores, la balanza de pagos.
Como no puede ser de otra manera, la falta de diversificación, que alentó las importaciones, tuvo como "telón de fondo" la reducida inversión industrial. La verificación de esta afirmación tropieza, sin embargo, con un problema central que tiene que ver con la ausencia de estadísticas de inversión sectoriales en las cuentas nacionales. Si bien esta es una falencia insalvable, existen abordajes parciales que tienden a constatar que tal afirmación no carece de sustento empírico con las evidencias disponibles.

Una primera forma de aproximarse a la problemática planteada es a través de evaluar el comportamiento inversor de las grandes empresas industriales a partir de la Encuesta Nacional a Grandes Empresas del INDEC. Se trata de un panel que, en promedio, albergó a 294 empresas entre 2003 y 2015, y cuyo valor agregado representó el 59,5\% del PIB industrial en ese período. Es decir, una muestra pequeña en materia de cantidad de empresas, pero que es decisiva en el devenir sectorial, tanto por su elevada concentración económica como por el hecho de estar integrada por numerosos oligopolios industriales, que son dominantes en sus respectivos mercados.

Así, en los datos aportados por la Figura 5 se advierte que la tasa de inversión de las grandes empresas industriales fue de tan solo el $11,1 \%$, sobre el valor agregado, entre 2003 y 2015. Se trata de un nivel que fue apenas superior a los requerimientos resultantes de las depreciaciones del capital que insume el proceso productivo, fue inferior al registrado durante los años noventa y fue sistemáticamente menor a la tasa de inversión nacional.

Tampoco se advierten, con excepción de 2006, modificaciones en la evolución de la inversión de las corporaciones fabriles de mayor tamaño entre 2003 y 2015, lo que sí ocurrió con la tasa de inversión nacional y su importante proceso de inversión, que se vio interrumpido a partir de 2008 con la irrupción de la crisis mundial y la emergencia de la restricción externa, pocos años después. Por su parte, en las compañías industriales, la inversión alcanzó apenas el $11,6 \%$ del valor agregado durante la primera administración kirchnerista (2003-2007), a pesar de contar con ganancias extraordinarias (Manzanelli, 2016). Luego, tras poner en funcionamiento la 
Figura 5. Tasa de inversión nacional y de las grandes empresas industriales*, 1993-2015 (en porcentajes del PIB)

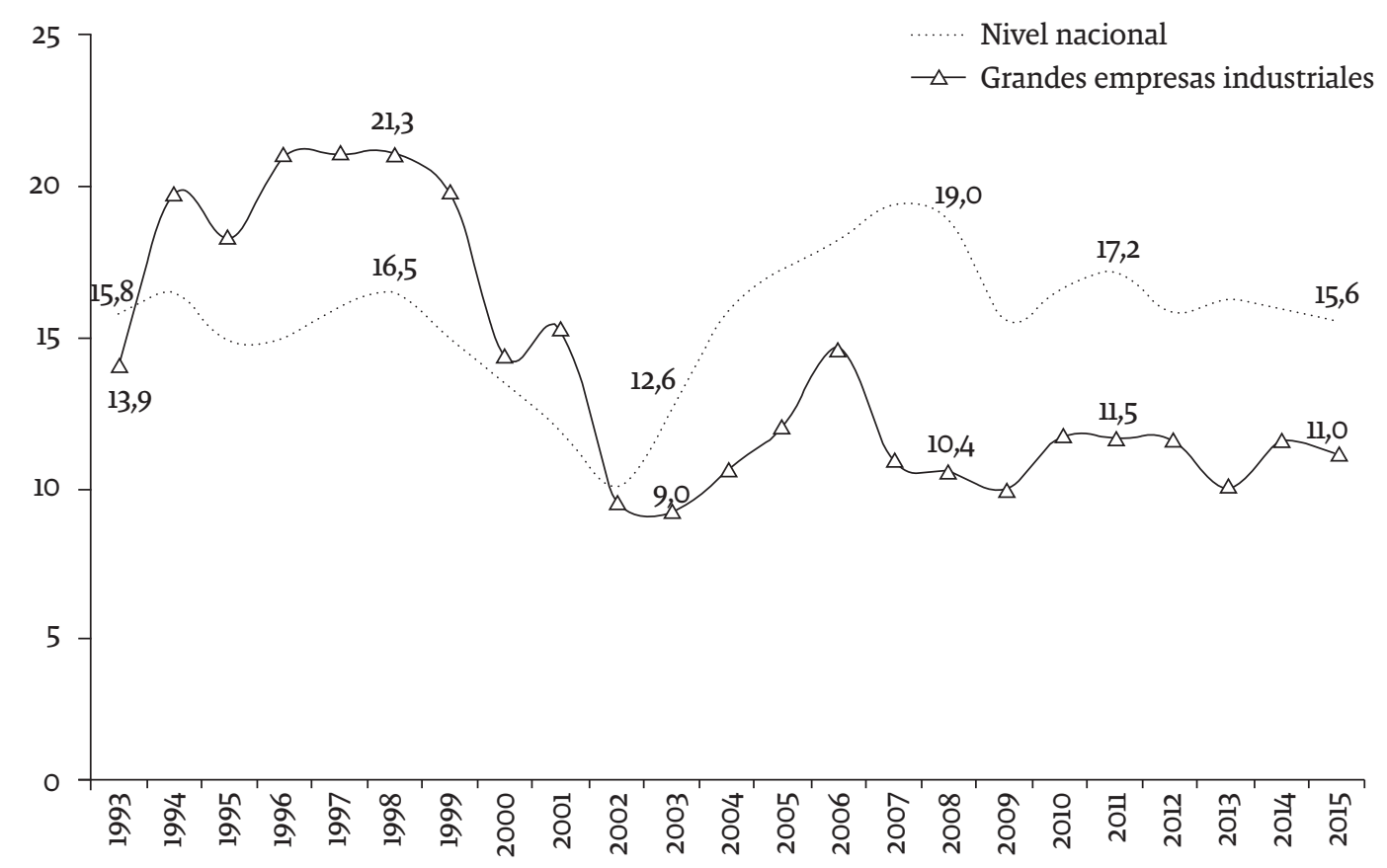

Nota: *Se trata de la inversión bruta interna fija sobre el PIB o el valor agregado bruto a precios corrientes. Las grandes empresas son las industriales, que alcanzaron a integrar el panel de las 500 empresas de mayor tamaño del país.

Fuente: elaboración propia basada en INDEC (2018).

casi totalidad del stock de capital preexistente en un proceso de fuerte impulso a la demanda, la formación bruta de capital en las firmas industriales trepó a su mayor nivel en $2006(14,6 \%)$, para luego sostenerse en torno a la media del período: entre 2008 y 2015, las grandes corporaciones industriales invirtieron el $11,0 \%$ del valor agregado. En tanto que, para el promedio del período 2012-2015, la tasa de inversión se ubicó también en el 11,0\%.

Resulta interesante advertir, por un lado, que -ante la emergencia de la restricción externa y la acentuación de diversos desequilibrios macroeconómicos- el desempeño de la inversión de las grandes industrias de la economía argentina se mantuvo inmutable; siempre en un bajo nivel. Por el otro, que en la generalidad de los casos se trató de un contexto operativo signado por una elevada rentabilidad en términos históricos, un fuerte impulso al consumo en prácticamente todo el período y una tendencia a una mayor utilización de capacidades ociosas después de la crisis de 1998-2002 (Figura 6). Es decir, un escenario en el que los factores locales que tienden a alentar las decisiones de inversión en el ámbito productivo resultaron favorables. De allí que se trate de un fenómeno que puede ser caracterizado como de baja propensión inversora por parte de las grandes compañías fabriles (Manzanelli, 2016).

9 Al respecto, cabe señalar que, para Kalecki (1995) “son tres los factores que (con el debido período de tiempo) determinan la inversión por unidad de tiempo en capital fijo: 1) el ahorro bruto "interno" actual de las empresas; 2) la tasa de crecimiento de las ganancias; y 3) la tasa de aumento del volumen de equipo de capital. Los primeros dos elementos son positivos y el tercero, negativo" (p. 160). Diversos autores avanzaron, posteriormente, en la necesidad de considerar el grado de utilización de la capacidad instalada (Amadeo, 1986; Lavoie, 1995) y la variación de la demanda en la medida en que incide en las expectativas de la realización de las ventas y en la rentabilidad esperada (Skott, 1989). Algo no muy distinto del rol de las expectativas que le asigna la visión keynesiana. 
Figura 6. Tasa de utilidad sobre valor de producción de las grandes empresas industriales*, y evolución del consumo privado total y del grado de utilización de la capacidad instalada en la industria, 1993-2015 (en porcentajes e índice base $2003=100$ )

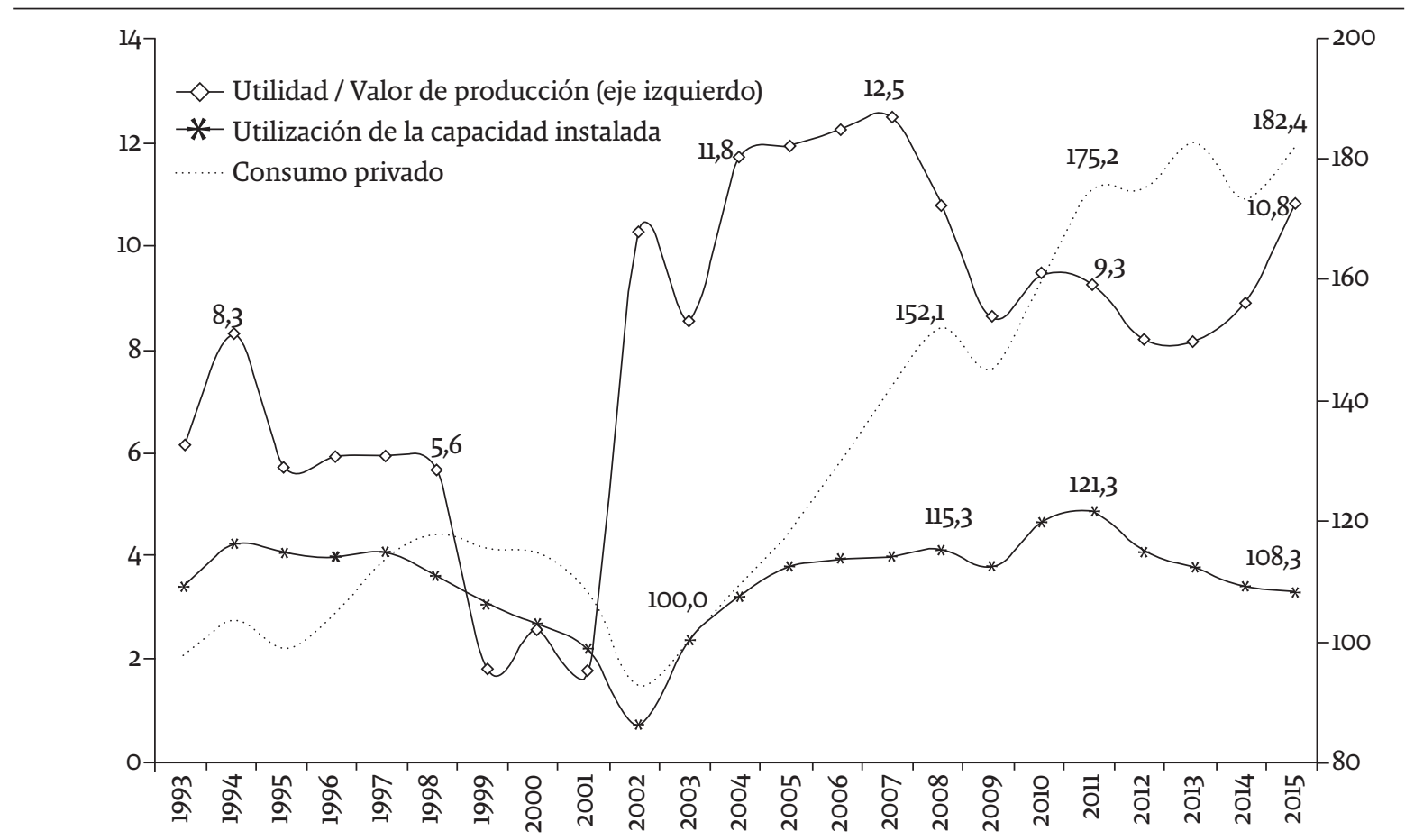

Nota: *Las grandes empresas son las industriales que alcanzaron a integrar el panel de las 500 empresas de mayor tamaño del país.

Fuente: elaboración propia basada en INDEC (2018).

Cabe señalar que diversas investigaciones demostraron que la estructura industrial heredada del modelo de valorización financiera denota no solo un elevado grado de concentración industrial, sino también una significativa extranjerización económica, en especial en el ámbito de la cúpula industrial (véase, por ejemplo, Manzanelli y Schorr, 2012). Ello invita a incorporar otros elementos para avanzar en el examen del fenómeno y del sustento empírico de la hipótesis de la subinversión, en el ámbito manufacturero.

En este sentido, resulta interesante observar el comportamiento inversor de las transnacionales en el exterior, de modo tal que se distinga si el reducido nivel de inversión observado para el caso argentino se corresponde (o no) con un comportamiento similar en otros países. Esto puede realizarse mediante los datos aportados por la Survey of Current Bussines, que capta la tasa de inversión bruta sobre el valor agregado de las filiales industriales de los Estados Unidos, según un conjunto de zonas económicas de relevancia: Argentina, Brasil y México -en el caso de América Latina-, China, los tigres asiáticos y los países centrales. Se trata de un conjunto de países representativo del comportamiento de las filiales norteamericanas, ya que explican alrededor del $70 \%$ del valor agregado de las filiales de los Estados Unidos en el período 2002-2015.

En los datos aportados por la Figura 7 se corrobora el fenómeno estudiado: las filiales industriales de los Estados Unidos manifestaron una baja tasa de inversión en la Argentina, que alcanzó apenas el 8,9\% sobre el valor agregado en el período 2003-2015. Se trata del registro 
Figura 7. Tasa de inversión de las filiales industriales norteamericanas en zonas seleccionadas*, 2003-2015 (en porcentajes del valor agregado)

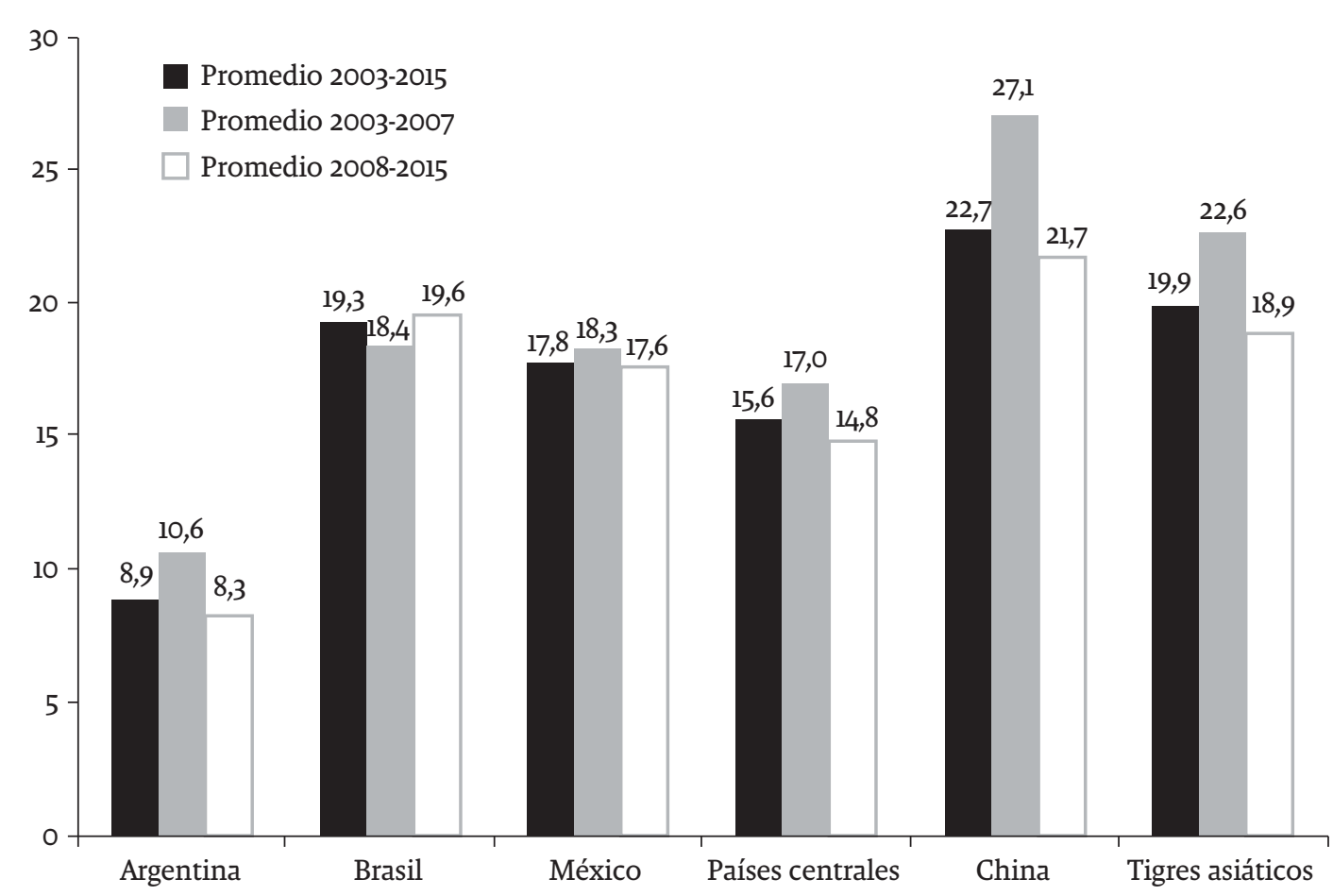

Nota: *La tasa de inversión es definida como la adición del gasto de capital y la I+D, y la relación con el valor agregado bruto. Los países centrales incluyen a Estados Unidos, Japón, Alemania, Francia, Reino Unido, Italia, España y Canadá, en tanto que los "tigres asiáticos" se refieren a Corea del Sur, Hong Kong, Singapur, Taiwán, Indonesia, Tailandia y Malasia.

Fuente: elaboración propia basada en U.S. Bureau of Economic Analysis (2018).

más bajo de las economías seleccionadas, tanto si se lo contrasta para el promedio del período 2003-2015 como para las distintas etapas que se pueden distinguir en el ciclo de la inversión nacional durante los gobiernos kirchneristas (2003-2007 y 2008-2015).

Como sostienen Milberg y Winkler (2013), la tendencia a la deslocalización de la gama estratégica de la firma y la búsqueda de una mayor flexibilidad a la diversificación de la propiedad tiene como fundamento principal el de reducir riesgos y esencialmente costos de producción, con el fin de maximizar la rentabilidad global de la firma. Sea por los menores salarios en China, México y algunos países de los tigres asiáticos, por la superior productividad media de los países centrales, y/o por la instalación de Brasil o México como base de operaciones continental, debido al elevado tamaño de su mercado interno, lo cierto es que la economía argentina quedó relegada en la orientación geográfica de la inversión industrial de las transnacionales norteamericanas.

Ello invita a reflexionar en torno a los cambios que se suscitaron en los condicionantes de la inversión durante la internacionalización productiva, la extensión de las cadenas globales de valor y la vigencia de economías abiertas a partir de los años ochenta. En ese marco, los determinantes a la inversión señalados en la visión kaleckiana, como también en la keynesiana -como es el caso de la expansión del consumo 
y la rentabilidad-, constituyen una condición necesaria, pero no suficiente para impulsar los proyectos de inversión de las empresas transnacionales. Cuyas decisiones, tal como lo sostiene Arceo (2011), tienden a subordinarse a la búsqueda por reducir los costos absolutos en la escala global.

Bajo estas circunstancias, las políticas fiscales, monetarias y de ingresos expansivas que se implementaron durante el ciclo de gobiernos kirchneristas, o las políticas cambiarias (el tipo de cambio alto de la primera etapa que encareció las importaciones), resultaron impotentes para generar por sí mismas las condiciones para la inversión manufacturera en un escenario de elevada concentración y extranjerización industrial.

\section{Política industrial, talón de Aquiles y experiencias incipientes}

El desempeño trunco de la industria en esta etapa no hace otra cosa que poner de manifiesto las falencias que existieron en la intervención estatal en el ámbito industrial. Es decir, la reducida propensión inversora de las corporaciones fabriles no solo exhibe sus propias estrategias, sino también la incapacidad del rol del estado para direccionar el desarrollo de las fuerzas internas que actúen para reorientar el papel inversor.

Si bien es innegable que las iniciativas en este sentido, durante el ciclo kirchnerista, fueron insuficientes, como lo señala buena parte de la literatura (Abeles y Amar, 2017; Kulfas, 2016; Manzanelli y Basualdo, 2017; Lavarello, 2017; Lavarello y Sarabia, 2015; Porta, Santarcángelo y Schteingart, 2014; Schorr, 2013; entre otros), resulta interesante pasar revista a algunas experiencias incipientes que se ensayaron al respecto y que permiten poner de relieve diversas estrategias estatales. Estrategias que pueden promover el proceso de formación de capital en un escenario internacional sumamente complejo como el actual.

Cabe señalar que, durante el período 20032007, la promoción al sector industrial, más allá de los regímenes preexistentes y algunas iniciativas de escasa envergadura, se limitó en lo esencial a la sostenibilidad de un tipo de cambio competitivo combinado con derechos de exportación inferiores para los productos industriales. Sin embargo, a partir de 2008 se desplegaron una serie de medidas que, aun no siendo suficientes, incrementaron la injerencia estatal, tanto en la producción directa de bienes y servicios como a través de estímulos a la actividad privada por medio de la demanda estatal y las políticas crediticias (Lavarello, 2017; Gerchunoff y Llach, 2018).

Entre las políticas industriales de larga data cabe señalar que, a partir de 2008 , se incrementaron de manera considerable los recursos fiscales y financieros dirigidos hacia la promoción del sector (Lavarello y Sarabia, 2015) y, fundamentalmente, se destaca la mayor relevancia que fue asumiendo el régimen de Tierra del Fuego como receptor de la promoción estatal. Al respecto, no solo se permitió la reapertura del régimen para la presentación de nuevos proyectos (fabricación de celulares y computadoras portátiles), sino que también se implementaron medidas de protección a las importaciones ${ }^{10}$. Asimismo, se instrumentaron un conjunto de medidas que ampliaron la demanda de los bienes electrónicos a partir del poder de compra del Estado -como fue el Plan Conectar Igualdad- o la puesta en marcha de programas que impulsaron el crédito personal para consumo con tarjetas de crédito -Ahora 12-. Los efectos del estímulo estatal sobre el sector se tradujeron, como se señaló anteriormente, en una importante tasa de crecimiento, aunque también en un mayor nivel de importaciones. Debido a estos resultados, se generaron múltiples trabajos que analizaron desde diversas ópticas, cuyo eje de discusión giró en torno a la viabilidad económica del régimen fueguino ${ }^{11}$.

Sin embargo, lo que interesa recalcar aquí no son las políticas que tendieron a afianzar la estructura industrial vigente (y con ella, la elevada

10 En 2009, se sancionó la Ley $\mathrm{N}^{\circ} 26.539$ que dispuso el incremento de los alícuotas de los impuestos pagados internamente por los productos de electrónica de consumo (con excepción de notebooks y netbooks). Una vez sancionada esta Ley entró en vigencia el Decreto $\mathrm{N}^{\circ}$ 252/2009, que dispuso una disminución de la alícuota pagada por los productos electrónicos fabricados dentro del Régimen Industrial de Tierra del Fuego.

11 Ver Schorr y Porcelli (2014), Santarcángelo y Perrone (2015) y Sanchez (2018). 
elasticidad de importaciones que se examinó previamente), sino aquellas experiencias incipientes que, de haber alcanzado una magnitud y maduración superior, podrían haber actuado como vía inductora de una mayor inversión y diversificación sectorial.

En este sentido, un primer caso a señalar es el creciente peso que asumieron las políticas orientadas a la generación de capacidades tecnológicas (software, biotecnología y nanotecnología) y a la infraestructura de ciencia y tecnología, no solo a través de los recursos destinados a tales fines desde el Ministerio de Ciencia y Tecnología, sino de organismos descentralizados como el Instituto Nacional de Tecnología Agropecuaria (INTA), el Instituto Nacional de Tecnología Industrial (INTI), la Comisión Nacional de Actividades Espaciales (CONAE), la Comisión Nacional de Energía Atómica (CNEA) y la Dirección de Fabricaciones Militares, cuyos presupuestos fueron más que duplicados en esta etapa (Figura 8).
El segundo caso relevante que vale mencionar es que, a partir de 2008 , la injerencia estatal directa en el proceso productivo tendió a adquirir mayor peso y se materializó a partir de distintas modalidades.

Una primera modalidad de intervención estatal es la que guarda relación con la participación del Estado como productor directo de bienes. El hito más importante, en este sentido, fue la expropiación del 51\% del paquete accionario de YPF, aunque también fue relevante, en el marco del mencionado aliento a los proyectos satelitales, nucleares y defensa, el aumento de los fondos orientados a financiar empresas estatales como INVAP, ARSAT y, en menor medida, Fabricaciones Militares.

En el caso de YPF, cabe apuntar no solo a su cambio de paradigma en materia de inversiones respecto a la conducción de Repsol, sino también a cierto desarrollo de proveedores, teniendo en cuenta la sustitución de importaciones de ciertos productos. En este marco, se

Figura 8. Evolución del gasto público ejecutado en precios constantes* en organismos seleccionados, 2007-2015 (índice base 2007=100)

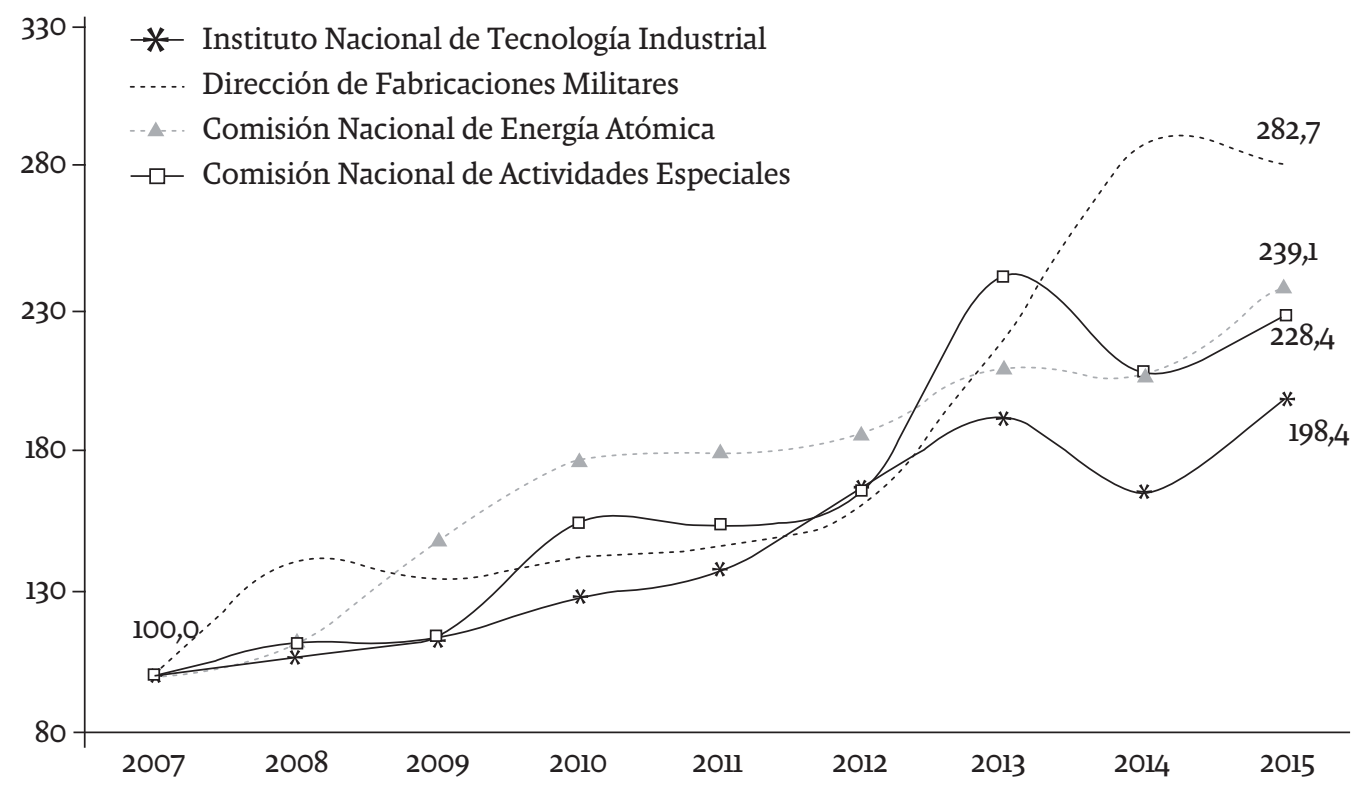

Nota: *Deflactado según el IPC Provincias.

Fuente: elaboración propia basada en el Ministerio de Hacienda (2018) y CIFRA (2017). 
inscribieron los Programas Sustenta, el proyecto de sustitución de importaciones de arenas de fractura y la iniciativa de la empresa YPF tecnología Y-TEC (Barrera, Kennedy y Palermo, 2015).

Por otro lado, la Empresa ARSAT -creada en 2006 con control mayoritario por parte del Estado-se ocupó de poner en órbita dos satélites geoestacionarios de comunicaciones (ARSAT 1, en 2014; ARSAT 2, en 2015), a la vez que comenzó con la construcción de un tercero. Con excepción del lanzamiento al espacio, la mayoría de las tareas involucradas en la fabricación de ambos satélites se realizaron en el país y con capital estatal ${ }^{12}$. Cabe mencionar que su relevancia no solo es cualitativa, ya que en este período canalizó el 1,9\% de los subsidios ejecutados y su inversión representó el 0,4\% de la inversión bruta interna fija del país; así como el $1,5 \%$ de la inversión en maquinaria y equipo del conjunto de la economía argentina, y el $7,0 \%$ de la inversión de las grandes empresas industriales (Figura 9). Además, para llevar a cabo estos proyectos se generó un interesante encadenamiento productivo que se constituyó como el núcleo articulador del complejo industrial espacial argentino, compuesto por distintos organismos estatales como la CONAE y la empresa estatal de Investigación aplicada INVAP. Esta última encargada de la fabricación de los satélites, el lanzador satelital en colaboración con la CONAE, la radarización y la elaboración de distintos trabajos en el área nuclear, en colaboración con la CNEA.

12 Asimismo, ARSAT S.A. implementó desde el año 2010 la Red Federal de Fibra Óptica y el Centro Nacional de Datos (Decreto 1552/10 -Poder Ejecutivo Nacional Argentino, 2010b-) enmarcados dentro del Plan Nacional de Telecomunicaciones Argentina Conectada y la plataforma de la Televisión Digital Abierta terrestre y satelital (Decreto 364/10 -Poder Ejecutivo Nacional Argentino, 2010a-). El objetivo de estos planes consistió en la expansión de la banda ancha y la TV digital a todo el país, llegando a espacios geográficos donde los operadores tradicionales no brindaban el servicio ni existía la infraestructura. Asimismo, esta empresa funcionó como instrumento para el desarrollo de políticas en telecomunicaciones que permitieron que el Estado se reposicione en el sector de información y comunicación como un actor relevante (Carrizo y Guido, 2013; Gennari y Lapuente, 2015).
Figura 9. Incidencia de la inversión y los subsidios percibidos de ARSAT en los respectivos agregados nacionales, Promedio 2013-2015 (porcentajes)

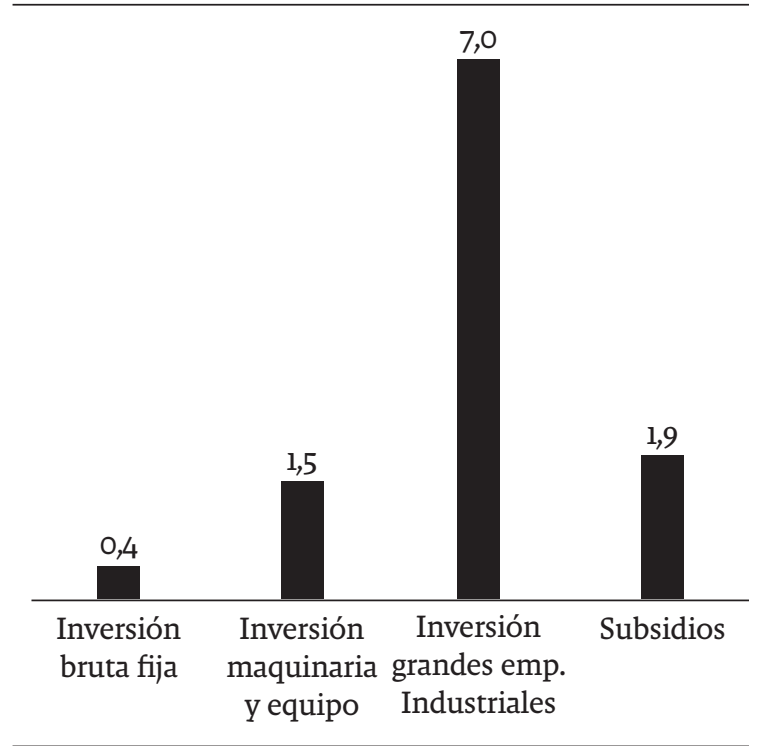

Fuente: elaboración propia basada en los balances empresarios, el Ministerio de Hacienda (2018) e INDEC (2018).

Como última experiencia del Estado, en su rol de empresario, cabe mencionar el impulso a la Dirección de Fabricaciones Militares. A partir de 2006 , se inició un proceso de transformación de esta Dirección para recomponer las capacidades operativas y fabriles de los diferentes establecimientos productivos que la componían y que habían sido discontinuados y/o privatizados en la década de $1990^{13}$. Se recuperó el Astillero Tandanor, el Astillero Almirante Domecq García y la Fábrica Militar de Aviones Brigadier San Martín (Eissa, 2010). No solo se evidencia un mayor gasto estatal en esta dependencia (Figura 8), sino que también se intentaron articular convenios con otros Ministerios para la producción de distintos bienes como chalecos antibalas y municiones (Arduino, 2014).

13 Esta Dirección Nacional tuvo bajo su control catorce plantas propias y participaciones accionarias en otras empresas. Luego del proceso de privatización solo quedaron bajo su cargo cuatro fábricas (Ministerio de Defensa, 2010). 
Ahora bien, entre las incipientes (e insuficientes) estrategias estatales orientadas a impulsar la actividad industrial, cabe mencionar un caso asociado a los estímulos estatales para la creación de capacidades técnicas en el ámbito privado. Así, por ejemplo en 2009, luego de la epidemia de la gripe A, el Estado decidió lanzar una licitación pública para la compra de vacunas antigripales por diez años, a cambio de la transferencia de capacidades tecnológicas al ámbito local ${ }^{14}$. Cabe señalar que la mayoría de las vacunas necesarias, para cumplimentar la ampliación del calendario de vacunación, se realizaban a través de importaciones (Corvalán, 2017). En 2010, se creó el consorcio de Cooperación Sinergium Biotech, conformado por una empresa multinacional -Novartis- y dos laboratorios nacionales pertenecientes al grupo Chemo-Insud (Elea y PharmADN), en el que también participaron distintas instituciones públicas y la Universidad Nacional de Quilmes. La licitación contempló el permiso de importación del producto final hasta lograr el desarrollo del antígeno en el ámbito local, a partir de la transferencia de conocimientos por parte de la multinacional Novartis y la construcción de una planta de producción de vacunas. Las inversiones necesarias para la concreción del proyecto estuvieron a cargo del consorcio mencionado. Posteriormente, se produjeron alianzas con otras empresas (Pzifer y Merck, Sharp \& Dohme) para la producción de otras vacunas, como es el caso de la vacuna neumocócica conjugada y la tetravalente contra el $\mathrm{VPH}^{15}$.

En efecto, este recorrido, si bien imperfecto, da cuenta de distintas estrategias adoptadas durante la segunda etapa kirchnerista, en torno a

14 Hasta ese momento, las compras de vacunas gubernamentales se realizaban a través de la Organización Panamericana de la Salud (OPS) o a firmas locales sin exigencia alguna de desarrollo de tecnología local (Lavarello, Minervini, Robert y Vázquez, 2019).

15 Resulta oportuno mencionar que, si bien esta iniciativa estatal fue relevante como instrumento para el incentivo de la inversión privada, no se registraron durante el mismo período políticas públicas dirigidas a fomentar los desarrollos científicos-técnicos de vacunas en los organismos públicos locales, como es el caso de VACSAL y CINDEFI (Corvalán, 2017). las modalidades que asumió la participación del Estado en el ámbito industrial. Se trata de experiencias incipientes de iniciativas estatales que, pese a su importancia cualitativa, no alcanzaron ni la dimensión ni la maduración tal como para consolidar, a través de las mismas, la conformación de un nuevo patrón de acumulación de capital basado en la producción industrial que sea sustentable en el tiempo.

\section{Conclusiones}

El interrogante básico que guio este trabajo es cómo la reducida inversión industrial tuvo un papel relevante en la interrupción del crecimiento sectorial, desde 2012 a la actualidad. Los hallazgos que se desprenden de la investigación indican que tal hipótesis no carece de sustento empírico, en lo que respecta al accionar del gran empresariado fabril.

$\mathrm{Al}$ respecto, se advierte una reducida tasa de inversión, tanto en lo que concierne a su desempeño en las grandes empresas industriales, que revela la Encuesta Nacional a Grandes Empresas (INDEC), como en lo que respecta a las comparaciones internacionales que se desprenden de la inversión industrial de las transnacionales norteamericanas, cuya información proviene de las Survey of Current Business (BEA).

La baja inversión industrial pone de relieve las dificultades para alentar un proceso de inversión industrial, en tiempos de la internacionalización productiva y la elevada transnacionalización de la estructura industrial en la economía argentina. Así, las políticas macroeconómicas expansivas, con énfasis en un acelerado crecimiento del consumo, y la elevada rentabilidad en buena parte del período 2003-2015, no fueron suficientes para estimular el proceso de inversión de las grandes compañías manufactureras.

A modo de hipótesis, para generar un activo proceso de industrialización se requería de una activa política industrial. Si bien, a partir de 2008 se advierten algunas experiencias interesantes en el área petrolera, aeroespacial y nuclear, a través de distintos organismos y/o empresas estatales (YPF, INVAP, ARSAT, entre las 
principales), tal como lo plantea la literatura especializada, esas políticas resultaron insuficientes para conducir un proceso de reindustrialización sostenible en el tiempo, que ensanche los campos de inversión sectoriales en sentido kaleckiano.

Bajo estas circunstancias, poco se avanzó para recuperar el bajo nivel de integración sectorial heredado de la valorización financiera (1976-2001). Esto redundó en un incremento de la elasticidad de las importaciones industriales, que solo se vio morigerada en el marco de la regulación de las mismas durante la emergencia de la restricción externa. Así, la subinversión fabril presionó sobre la balanza de pagos, tanto por el lado de las importaciones como por el de la salida de las ganancias no reinvertidas al exterior.

Como lo demuestran los procesos históricos -desde la experiencia francesa y alemana de los "campeones nacionales", durante el período de la posguerra, hasta el impulso de grandes grupos económicos diversificados: los Keiretsus japoneses o los Cheabols coreanos (Lavarello y Sarabia, 2015)-, no es la ausencia sino la activación del Estado la que puede alentar un proceso de industrialización. Más aún en tiempos de la globalización productiva.

\section{Referencias bibliográficas}

Abeles, M., y Amar, A. (2017). La industria manufacturera y su encrucijada. En M. Abeles, M. Cimoli y P. Lavarello (Eds.), Manufactura y cambio estructural: aportes para pensar la política industrial en la Argentina (pp. 11l-147). Santiago de Chile, Chile: CEPAL.

Amadeo, E. (1986). The Role of Capacity Utilization in Long-period Analysis. Political Economy, 2(2), 147-185.

Amico, F. (2013). Crecimiento, distribución y restricción externa en Argentina. Revista Circus, (5), 31-80.

Arceo, E. (2011). El largo camino a la crisis: centro, periferia y transformaciones en la economía mundial. Buenos Aires, Argentina: Cara o Ceca.

Arduino, I. (2014). Seguridad y defensa en Argentina. En C. Guarnizo (Ed.), Anuario 2014 de la seguridad regional en América Latina y el Caribe (pp. 17-51). Bogotá, Colombia: Programa de Cooperación en Seguridad Regional.

Azpiazu, D., y Schorr, M. (2010). Hecho en Argentina. Industria y economía, 1976-2007. Buenos Aires, Argentina: Editorial Siglo XXI.

Azpiazu, D., Basualdo, E., y Nochteff, H. (1988). La revolución tecnológica y las políticas hegemónicas. El complejo electrónico en Argentina. Buenos Aires, Argentina: Legasa.

Barrera, M., Kennedy, D., y Palermo, H. (2015). Impacto económico de YPF desde su renacionalización (Ley 26.741). Desempeño productivo e implicancias sobre los mercados laborales y el entramado de proveedores. Volumen I. Santiago de Chile, Chile: CEPAL. Recuperado de https://repositorio.cepal. org/bitstream/handle/11362/39398/S1501216_es.pdf?sequence=1\&isAllowed=y

Basualdo, E. (2003). Las reformas estructurales y el Plan de Convertibilidad durante la década de los noventa. Realidad Económica, (200), 42-82.

Basualdo, E. (2010). Estudios de historia económica Argentina: desde mediados del siglo XX a la actualidad. Buenos Aires, Argentina: Siglo XXI Editores. 
Bekerman, M., y Dulcich, F. (2018). Análisis comparativo de la Zona Franca de Manaos y el área aduanera especial de Tierra del Fuego. Economia e Sociedade, 26(3), 751-791.

Bekerman, M., Dulcich, F., y Gaite, P. (2018). La inserción comercial externa de la Argentina en la última década: su impacto sobre la estructura productiva. Revista de Historia de la Industria, los Servicios y las Empresas en América Latina H-industri@, 23(12), 115-142.

Braun, O., y Joy, L. (1968). A model of economic stagnation. A case study of the Argentine economy. The Economic Journal, 78(312), 868-887. doi: 10.2307/2229183

Broda, M., y Asociados. (2015). Informe semanal (1137). Recuperado de https://pdfslide.net/documents/ estudio-brodapdf.html

Carrizo, S., y Guido, L. (2013). Redes técnicas y políticas públicas en la Argentina desde fines de siglo $\mathrm{XX}$ : Cambios en el sector de tecnologías de información y comunicación. Revista de estudios regionales y mercado de trabajo, (9), 171-183.

Castells, M. J., y Schorr, M. (2015). Cuando el crecimiento no es desarrollo. Algunos hechos estilizados de la dinámica industrial en la posconvertibilidad. Cuadernos de Economía Crítica, 1(2), 49-77.

CIFRA -Centro de Investigación y Formación de la República Argentina-. (2017). Índice de Precios al Consumidor Provincias (IPC Provincias). Buenos Aires, Argentina: CIFRA.

CEP -Centro de Estudios para la Producción-. (2016). Fichas sectoriales del ex Ministerio de Industria. Buenos Aires, Argentina: CEP.

Coatz, D., y Schteingart, D. (2016). La industria en el siglo XXI: entre los avatares de la coyuntura y los desafíos estructurales. Boletín Informativo Techint(353). Recuperado dehttp://iosapp.boletintechint. com/Utils/DocumentPDF.ashx?Codigo=2e9f8d35-d63c-49bb-b10o-becf57d7cf25\&IdType=2

Corvalán, D. (2017). Des-aprendizaje y pérdida de capacidades locales. El calendario nacional de vacunación en Argentina. Ciencia, Docencia y Tecnología, 28(54), 1-37.

De la Torre, A., Levy Yeyati, E., y Pianknaguru, S. (2013). América Latina y el Caribe sin viento a favor: en busca de mayor crecimiento. LAC Semiannual Report. Washington D. C., Estados Unidos: Banco Mundial. doi: 10.1596/978-0-8213-9978-1

Diamand, M. (1973). Doctrinas económicas, desarrollo e independencia. Buenos Aires, Argentina: Editorial Paidós.

Eissa, S. (2010). Lo que el neoliberalismo se llevó: reconstruyendo la política de defensa argentina. Conferencia llevada a cabo en el V Congreso de Relaciones Internacionales, Facultad de Ciencias Jurídicas y Sociales, Universidad Nacional de La Plata, Buenos Aires, Argentina. Recuperado de http://sedici.unlp.edu.ar/handle/10915/40346

Fernández-Bugna, C., y Porta, F. (2007). El crecimiento reciente de la industria argentina. Nuevo régimen sin cambio estructural. En B. Kosacoff (Ed.), Crisis, recuperación y nuevos dilemas. La economía argentina, 2002-2007 (pp. 63-107). Buenos Aires, Argentina: CEPAL.

Ferreres, O. (2004). Dos siglos de economía argentina, 1810-2004. Buenos Aires, Argentina: Editorial El Ateneo.

Frenkel, R., Damill, M., y Rapetti, M. (2015). Macroeconomic Policy in Argentina during 2002-2013. Comparative economic studies, 57(3), 369-400. doi: 10.1057/ces.2015.3 
Gennari, M., y Lapuente, S. (2015). El Arsat-1 y su vinculación con la Televisión Digital Abierta como política pública promovedora de inclusión social. Actas de periodismo y comunicación, 1(2), 1-15.

Gerchunoff, P., y Llach, L. (2018). El ciclo de la ilusión y el desencanto. Buenos Aires, Argentina: Editorial Crítica.

Goldstein, E., Kulfas, M., y Zack, G. (2017). Desempeño industrial y restricción externa en la Argentina (2003-2012). Revista de Historia de la Industria, los Servicios y las Empresas en América Latina H-industri@,11(21), 97-120.

González, M., y Manzanelli, P. (2012). La industria en la posconvertibilidad. El caso del complejo automotor (Documento de trabajo No. 25). Buenos Aires, Argentina: Área de Economía y Tecnología de la FLACSO. Recuperado de http://publicacioneseconomia.flacso.org.ar/images/pdf/1.83.pdf

INDEC -Instituto nacional de Estadísticas y Censos-. (2018). Estadísticas de Cuentas Nacionales e Industria Manufacturera. Recuperado de https://www.indec.gob.ar/

Kalecki, M. (1995). Ensayos escogidos sobre dinámica de la economía capitalista. México D. F., México: Fondo de Cultura Económica.

Kulfas, M. (2016). Los tres kirchnerismos. Una historia de la economía argentina, 2003-2015. Buenos Aires, Argentina: Editorial Siglo XXI.

Lavarello, P. (2017). El incompleto (y breve) regreso de la política industrial: el caso de la Argentina 2003-2015. Problemas del Desarrollo, 190(48), 109-135. doi: 10.1016/j.rpd.2017.06.005

Lavarello, P., y Sarabia, M. (2015). La política industrial en la Argentina durante la década del 2000 (Serie Estudios y Perspectivas No. 45). Buenos Aires, Argentina: CEPAL. Recuperado de https:// repositorio.cepal.org/bitstream/handle/11362/39886/1/S1600018_es.pdf

Lavarello, P., Minervini, M., Robert, V., y Vázquez, D. (2019). Las políticas orientadas por misiones: el debate en los países centrales y su aplicación en el contexto de países en desarrollo. En D. Suárez, A. Erbes y F. Barletta (Comp.), Teoría de la innovación: evolución, tendencias y desafíos. Herramientas conceptuales para la enseñanza y el aprendizaje (mimeo). Buenos Aires, Argentina: Editorial UNGS.

Lavoie, M. (1995). The Kaleckian model of growth and distribution and its neo-Ricardian and neoMarxian critiques. Cambridge Journal of Economics, (19), 789-818. doi: 10.1093/oxfordjournals.cje. a035341

Levy-Yeyati, E., y Castro, L. (2012). Radiografía de la industrialización argentina en la posconvertibilidad (Documento de políticas públicas No. 112). Buenos Aires, Argentina: Centro de Implementación de Políticas Públicas para la Equidad y el Crecimiento. Recuperado de https://www.cippec.org/wpcontent/uploads/2017/03/2163.pdf

Levy-Yeyati, E., y Cohan, L. (12 de enero, 2012). What have I done to deserve this? Global winds and Latin American growth [Mensaje en un blog]. Recuperado de https://voxeu.org/article/ uncoupling-decoupling-latin-america-s-experience

Manzanelli, P. (2016). Grandes empresas y estrategias de inversión en la Argentina 2002-2012. Desarrollo Económico, 56(218), 33-58. 
Manzanelli, P. (2019). ¿En el mundo del revés? La cúpula empresaria y la inversión en la Argentina 2002-2017. Realidad Económica, (321), 9-34.

Manzanelli, P., y Basualdo, E. (2017). La era kirchnerista. El retorno de la economía real, el desendeudamiento externo y las pugnas por la distribución del ingreso, 2003-2015. En E. Basualdo (Coord.), Endeudar y fugar. Un análisis de la historia económica argentina, de Martínez de Hoz a Macri (pp. 103-146). Buenos Aires, Argentina: Editorial Siglo XXI.

Manzanelli, P. y Schorr, M. (2012). Extranjerización y poder económico industrial en Argentina. Problemas del Desarrollo, 43(170), 39-67. doi: 10.22201/iiec.20078951e.2012.170.32135

Milberg, W., y Winkler, D. (2013). Outsourcing economics: global value chains in capitalist development. Nueva York, Estados Unidos: Cambridge University Press.

Ministerio de Defensa. (2010). Libro blanco de la Defensa. Buenos Aires, Argentina. Recuperado de https://www.files.ethz.ch/isn/157079/Libro_Blanco_de_la_Defensa_spanish.pdf

Ministerio de Hacienda. (2018). Datos de ejecución presupuestaria nacional. Recuperado de https:// www.minhacienda.gob.ar/onp/presupuestos/2018

Ministerio de Producción y Trabajo. (2018). Estadísticas de comercio y producción industria manufacturera. Buenos Aires, Argentina: Ministerio de Producción y Trabajo.

Nochteff, H. (1984). Desindustrialización y retroceso tecnológico en Argentina 1976-1982. Buenos Aires, Argentina: FLACSO-GEL.

Poder Ejecutivo Nacional Argentino. (1972). Ley $N^{o}$ 19.640/72. Recuperado de http://servicios.infoleg. gob.ar/infolegInternet/anexos/25000-29999/28185/norma.htm

Poder Ejecutivo Nacional Argentino. (2010a). Decreto 364/10. Recuperado de http://servicios.infoleg. gob.ar/infolegInternet/anexos/175000-179999/175266/norma.htm

Poder Ejecutivo Nacional Argentino. (2010b). Decreto 1552/10. Recuperado de http://servicios.infoleg. gob.ar/infolegInternet/verNorma.do?id=174110

Porta, F., y Fernández-Bugna, C. (2011). La industria manufacturera: trayectoria reciente y cambios estructurales. En R. Mercado, B. Kosacoff y F. Porta (Eds.), La Argentina del largo plazo: crecimiento, fluctuaciones y cambio estructural (pp. 83-125). Buenos Aires, Argentina: PNUD.

Porta, F., Santarcángelo, J., y Schteingart, D. (2014). Excedente y desarrollo industrial en Argentina: Situación y desafíos (Documento de Trabajo No. 59). Buenos Aires, Argentina: CEFIDAR. Recuperado de http://www.iade.org.ar/system/files/dt59.pdf

Sanchez, M. (2018). La industria electrónica de consumo en Argentina: un aporte al estudio de su desarrollo a partir del análisis de su localización. Revista de Historia de la Industria, los Servicios y las Empresas en América Latina H-industri@, (22), 40-70.

Santarcángelo, J., y Perrone, G. (2015). Desafíos y oportunidades del desarrollo de la electrónica de consumo en los países de desarrollo: lecciones del caso argentino (2003-2014). Revista Redes, 21(41), $13-40$.

Schorr, M. (2013). Argentina en la posconvertibilidad: ¿desarrollo o crecimiento industrial? Estudio de economía política. Buenos Aires, Argentina: Ediciones Miño y Dávila. 
Schorr, M., y Porcelli, L. (2014). La industria electrónica de consumo en Tierra del Fuego. Régimen promocional, perfil de especialización y alternativas de desarrollo sectorial en la posconvertibilidad (Documentos de investigación social No. 26). Buenos Aires, Argentina: IDAES.

Schorr, M., y Wainer, A. (2017). La economía argentina bajo el kirchnerismo: de la holgura a la restricción externa. En A. Pucciarelli y A. Castellani (Comps.), Los años del kirchnerismo. La disputa hegemónica tras la crisis del orden neoliberal (pp. 119-174). Buenos Aires, Argentina: Editorial Siglo XXI.

Skott, P. (1989). Effective Demand, Class Struggle and Cyclical Growth. International Economic Review, 30(1), 231-247. doi: 10.2307/2526560

U.S. Bureau of Economic Analysis. (2018). Estadísticas de inversión de las filiales industriales norteamericanas. Recuperado de https://apps.bea.gov/iTable/iTable.cfm?ReqID=2\&step=1 